\title{
EHMTI-0118. Risk factors of migraine - a co-twin control study
}

\author{
HD Hambardzumyan", HM Manvelyan \\ From 4th European Headache and Migraine Trust International Congress: EHMTIC 2014 \\ Copenhagen, Denmark. 18-21 September 2014
}

\section{Introduction}

Migraine is a very frequent disease in Armenia.

\section{Aims}

To evaluate the effect of a variety of diseases and environmental risk factors on the risk of migraine.

\section{Methods}

In 2012, more than 10.000 twin individuals participated in a questionnaire survey. Only complete same-sexed twin pairs discordant for migraine were included in this co-twin control study, which comprised 554 female and 325 male pairs. This design allowed us to control for most shared genetic and environmental predisposition.

\section{Results}

Low back pain, neck pain and whiplash were significantly associated with migraine with an increased risk of 50-110\%. Arterial hypertension, kidney stone, osteoarthritis and tinnitus were also significantly associated with migraine. Coronary thrombosis and other thrombosis as separate entities were not associated with migraine, however, when pooled together there was significantly increased $\operatorname{risk}(\mathrm{OR}=1.88[1.14-3.08], \mathrm{p}=0.01)$. Weekly alcohol consumption was the only environmental factor significantly associated with migraine. The risk was decreased with almost $20 \%$. The effect of obesity on the risk of migraine was 1.5 , however, this was not statistically significant $(\mathrm{p}=0.07)$.

\section{Conclusions}

This is the first large co-twin study of co-morbidities and environmental risk factors in migraine. A number of co-morbidities were confirmed but no environmental risk factors besides alcohol consumption were

Neurology, Yerevan State Medical University, Yerevan, Armenia significant. Alcohol is a potent inducer of migraine attack therefore the association between alcohol and migraine is likely due to an avoidance reaction towards alcohol. Conventional socio-economic and lifestyle factors therefore do not seem to be important. Further studies should focus on other factors, e.g. emotional factors such as stressful events.

No conflict of interest.

Published: 18 September 2014

doi:10.1186/1129-2377-15-S1-G14

Cite this article as: Hambardzumyan and Manvelyan: EHMTI-0118. Risk factors of migraine - a co-twin control study. The Journal of Headache and Pain 2014 15(Suppl 1):G14.

Submit your manuscript to a SpringerOpen ${ }^{\odot}$ journal and benefit from:

- Convenient online submission

- Rigorous peer review

- Immediate publication on acceptance

- Open access: articles freely available online

- High visibility within the field

- Retaining the copyright to your article

Submit your next manuscript at $>$ springeropen.com (c) 2014 Hambardzumyan and Manvelyan; licensee Springer. This is an Open Access article distributed under the terms of the Creative Commons Attribution License (http://creativecommons.org/licenses/by/2.0), which permits unrestricted use, distribution, and reproduction in any medium, provided the original work is properly cited. 